\title{
Análise da inclusão da educação ambiental no processo de licenciamento de empreendimentos no sul do Estado de Minas Gerais, Brasil
}

\section{Amanda Domingas Ediodato de Sousa*, Cleir Ferraz Freire, Felipe Zauli da Silva, Fernando da Costa Correa, Adriana Maria Imperador e Luciana Botezelli}

Universidade Federal de Alfenas. Programa de Pós-Graduação em Ciências Ambientais. Rodovia José Aurélio Vilela, 11999. Cidade Universitária. Poços de Caldas-MG, Brasil (CEP 37715-400).*E-mail: amandaediodato@gmail.com.

Resumo. O licenciamento ambiental é uma exigência legal administrativa a partir da qual o Poder Público promove o controle ambiental e dentro deste processo é obrigatório a inserção de programas de Educação Ambiental. Visando a verificar a efetividade e importância dadas ao tema nos empreendimentos licenciados com Estudo de Impacto Ambiental (EIA) e respectivo Relatório de Impacto Ambiental (RIMA) no sul de Minas Gerais foram consultadas as informações indicadas pela Secretaria de Estado de Meio Ambiente e Desenvolvimento Sustentável de Minas Gerais dos processos de licenciamento desta modalidade entre os anos de 2015 e 2019. A partir das informações fornecidas foi realizada a sistematização e tabulação dos dados encontrados relacionados a aspectos de educação ambiental. Apesar de $28 \%$ dos empreendimentos não citar ou abordar a temática nos processos, muitos dos demais não dispunham de um projeto consistente neste tema. Mesmo com experiências negativas de desastres ambientais no Estado de Minas Gerais demonstrando a importância da educação ambiental nos processos de licenciamento e que a exigência de um programa robusto neste sentido continua sendo negligenciado.

Palavras-chave: Avaliação de impacto ambiental; Gestão ambiental; Programa de educação ambiental.

Abstract. Analysis of the inclusion of environmental education in the enterprise licensing process in the southern State of Minas Gerais, Brazil. Environmental license is a legal requirement from which Public Power promotes environmental control and in this processes insertion of environmental education programs is an obligation. Aiming to verify effectivity and importance due on this issue on enterprises licensing with Environmental Impact Studies and Environmental Impact Report on the southern of Minas Gerais information of the Secretary of Environmental and Sustainable Development of Minas Gerais about enterprises license by EIA/RIMA between 2015 and 2019
Recebido

$03 / 07 / 2020$

Aceito

$17 / 10 / 2020$

Disponível on line

$18 / 10 / 2020$

Publicado

$31 / 12 / 2020$

Acesso aberto

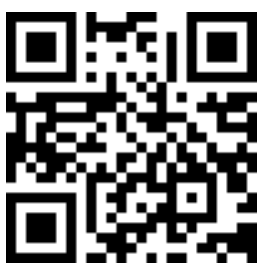

ORCID

(1) 0000-0002-1138-5220

Amanda Domingas

Ediodato de Sousa

D) 0000-0002-6113-2520

Cleir Ferraz Freire

(D) 0000-0002-6395-5424

Felipe Zauli da Silva

(D) 0000-0002-3652-4565

Fernando da Costa

Correa 
were consulted. From the information obtained was realized the systematization and tabulation of data related to environmental education. Although $28 \%$ of enterprises not even mention or approach environmental education on their process, much of others did not have a consistent project on this issue. Despite of negative experiences on environment disasters in the state of Minas Gerais demonstrate the importance of environmental education in the licensing process the requirement of a robust project in this direction is still neglected.

Keywords: Environmental impact assessment; Environmental management; Environmental education program.
(D) 0000-0002-9755-2586

Adriana Maria

Imperador

(ㄱ) 0000-0002-5916-0442

Luciana Botezelli

\section{Introdução}

A sustentabilidade do planeta, tema que ganhou destaque na mídia científica nos últimos anos, necessita de mecanismos legais e técnicos para promover a sua operacionalização. Foi com este pensamento que o legislador brasileiro consagrou, na Constituição de 1988 (Brasil, 1988), o princípio e a determinação da educação ambiental no país, como forma de conscientizar a população da necessidade de se preservar e defender o meio ambiente.

O licenciamento ambiental é uma exigência legal administrativa a partir da qual o Poder Público promove o controle ambiental, caracterizando localização, a instalação, a ampliação e a operação de empreendimentos e atividades utilizadoras de recursos ambientais, consideradas efetiva ou potencialmente poluidoras, ou que possam causar degradação ambiental de acordo com as legislações, regulamentos e normas técnicas aplicáveis ao negócio (Brasil, 2016; SEBRAE, 2004).

Todo empreendimento citado pela Resolução do Conselho Nacional de Meio Ambiente - CONAMA nº 237/1997, e outros que o órgão licenciador considerar necessário, considerando que a lista da resolução é exemplificativa, são obrigados a possuir a licença ambiental, cuja validade é emitida com tempo definido, na qual o órgão ambiental estabelece regras, condições, restrições e medidas de controle ambiental a serem seguidas por sua empresa (Brasil, 1997; SEBRAE, 2004; Minas Gerais, 2009).

Além das informações técnicas relacionadas ao licenciamento ambiental, os Programas de Educação Ambiental devem ser implementados nos empreendimentos como requisito básico de operação, buscando promover ações de conscientização, ensino e aprendizado que contemplem a comunidade e os trabalhadores envolvidos, proporcionando assim condições para que esses possam compreender como evitar, controlar ou mitigar os impactos socioambientais (Brasil, 2009; Minas Gerais, 2020).

Para obtenção do licenciamento ambiental, são exigidas em cada etapa um tipo específico de licença, sendo essas a licença prévia (LP), a licença de instalação (LI) e a licença de operação (LO). Na etapa da LP podem ser requeridos estudos ambientais complementares, tais como Estudo de Impacto Ambiental e o respectivo Relatório de Impacto Ambiental (EIA/RIMA), Relatório Ambiental Simplificado (RAS) e Relatório de Controle Ambiental (RCA) (Brasil, 2016).

As atividades com potencial e efetivamente poluidoras devem ser controladas, com ações preventivas e corretivas e não podem ser desenvolvidas em qualquer lugar, estando sujeitas a leis especiais. Ainda a implantação da educação ambiental em todos os níveis de ensino de forma transversal e em toda a comunidade, buscando uma postura sustentável da sociedade, garantindo assim uma participação mais efetiva na defesa do meio ambiente. 
Em relação ao Estado de Minas Gerais, a definição de implementação do licenciamento ambiental é dada pelo próprio empreendedor através do primeiro estágio, que é o preenchimento da Ficha de Caracterização do Empreendimento (FCE). Nesta etapa os empreendimentos são classificados e os que necessitam de EIA/RIMA são orientados em relação ao processo, que passa a ser capitaneado pelo órgão federal, Instituto Brasileiro do Meio Ambiente e dos Recursos Naturais Renováveis (IBAMA), sem prejuízo da participação do órgão ambiental estadual e demais instituições estaduais afins ao processo (Minas Gerais, 2020).

Concomitantemente, a educação ambiental, definida primeiramente como um processo de conscientização sobre a conservação e proteção da natureza, ganhou objetivo e definição mais ampla a partir dos anos 1980, e atualmente é entendida como uma educação política, que consiste em uma análise das relações políticas, econômicas, sociais e culturais entre a humanidade e a natureza e as relações entre os seres humanos, visando à superação dos mecanismos de controle e de dominação que impedem a participação livre, consciente e democrática de todos (Milaré, 2018).

Diante das definições apresentadas anteriormente e a temática da Ciência Ambiental associada ao licenciamento e educação ambiental, buscou-se analisar e descrever os mecanismos necessários para o licenciamento de empreendimentos no Sul de Minas Gerais, cuja atividade necessite de EIA/RIMA, e também, avaliar os efeitos que a educação ambiental possui sobre esse processo de implementação, a partir da conscientização e multiplicação com os agentes envolvidos. Diante desse ponto, buscou-se analisar os segmentos dos empreendimentos licenciados no Sul de Minas Gerais que possuem EIA/RIMA e avaliar os empreendimentos licenciados que possuem uma política de educação ambiental descrito no EIA/RIMA.

\section{Metodologia}

Para condução do estudo proposto, foram consultadas as informações indicadas pela Secretaria de Estado de Meio Ambiente e Desenvolvimento Sustentável (SEMAD), do Estado de Minas Gerais (Minas Gerais, 2020) dos empreendimentos licenciados por EIA/RIMA entre os anos de 2015 e 2019, localizados na Região da Superintendência do Sul de Minas Gerais (SUPRAM Sul de Minas), composta por 176 municípios (Minas Gerais, 2020). Para a realização do levantamento utilizou-se a metodologia descrita em Gil (1999).

Inicialmente, foi realizado contato com servidor da SUPRAM, localizada no Município de Varginha, o qual disponibilizou a planilha de Excel (dados de domínio público) com os empreendimentos licenciados entre 2015 e 2019 no Sul de Minas Gerais e, que o licenciamento foi realizado por meio de EIA/RIMA.

De posse da listagem dos empreendimentos foi realizada pesquisa sobre a disponibilização de informações nos órgãos ambientais, plataforma do Sistema Integrado de Informação Ambiental (SIAM), sendo esta a base de dados da Superintendência Regional de Meio Ambiente (SUPRAM) (Pereira e Gutierres, 2018). Além disso, foram acessados os sites das empresas em geral, acerca da transparência das atividades de educação ambiental, amplitude e impacto das ações, quando possível, e terceirização da realização destas atividades (SIAM, 2016).

A partir dos apontamentos encontrados, foi realizada a sistematização das informações e a tabulação dos dados encontrados relacionados a aspectos de educação ambiental. Adicionalmente, foram mapeados pontos correlatos com a educação ambiental com o enfoque de identificar ações que podem agregar valores ao empreendimento de maneira a multiplicar com as pessoas envolvidas a importância do respeito ao meio ambiente.

Rev. Bras. Gest. Amb. Sustent., 2020, vol. 7, n. 17, p. 1175-1182. 


\section{Resultados e discussão}

A partir dos dados disponibilizados numa planilha de Excel com os empreendimentos licenciados entre 2015 e 2019 no sul de Minas Gerais, que foram licenciados através de EIA/RIMA, foi possível dar início na análise das informações declaradas.

Ao todo foram licenciados 36 empreendimentos entre 2015 a 2019, desse total, foram excluídos das análises três arquivos por apresentarem dificuldades técnicas, dois processos licenciados no Município Poço Fundo e um processo no Município de Pouso Alegre. Além disso, um processo no Município de Congonhal estava apenas com o EIA/RIMA referente a 2012 disponível, sendo esse processo já vencido. Desta forma, foram analisados o total de 32 processos de licenciamentos.

A primeira análise realizada foi em relação aos municípios que possuíam empreendimentos licenciados com EIA/RIMA e a quantidade de licenciamentos neste período informado (Figura 1).

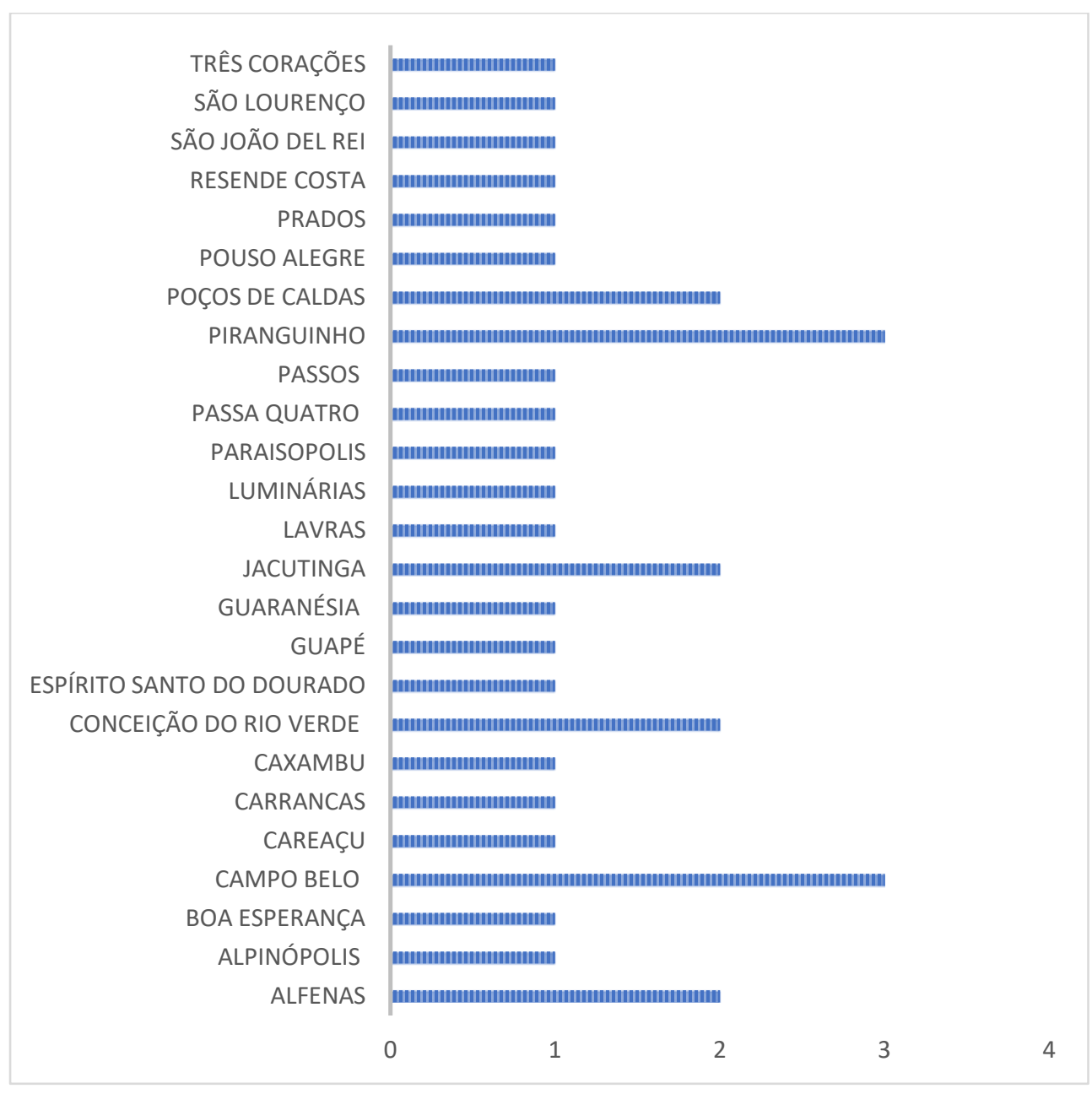

Figura 1. Total dos empreendimentos licenciados com EIA/RIMA no sul de Minas Gerais, fornecido pela SUPRAM. 
Foram analisados também o quantitativo de EIA/RIMA por ano. Conforme apresentado na Figura 2, o ano com maior número de empreendimentos licenciados foi em 2016, com 11 estudos. Apesar de 2019 apresentar somente um empreendimento licenciado acredita-se que esse valor se deve ao fato que o banco de dados ainda não estarem completamente atualizados.

Já em relação ao segmento dos empreendimentos licenciados, $75 \%$ representam o setor de mineração, com atividades como mineração de brita, quartzo, areia entre outros. 0 ramo outras atividades, representam o licenciamento de implementação de um distrito industrial e a implementação de dois aterros sanitários (Figura 3).

Por último, após analisar todos os EIA/RIMA dos empreendimentos em questão, os mesmos foram separados em empreendimentos que citam algum Programa de Educação Ambiental e empreendimentos que não citam (Figura 4). Dos nove empreendimentos listados que não citam o Programa de Educação Ambiental no EIA/RIMA, dois empreendimentos, um localizado em Alfenas e outro em Carrancas, citam o Programa de Educação Ambiental no Programa de Controle Ambiental.

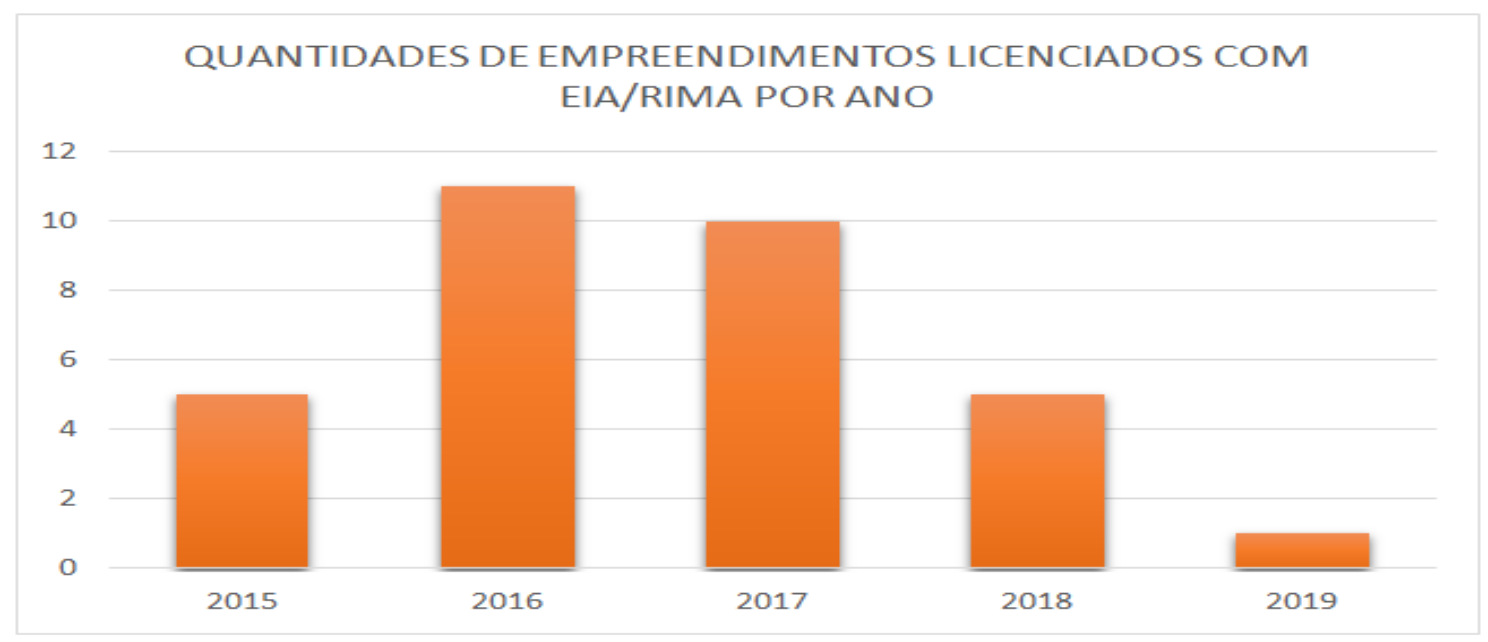

Figura 2. Quantidade de empreendimentos licenciados com EIA/RIMA no sul de Minas Gerais entre os anos de 2015 e 2019.

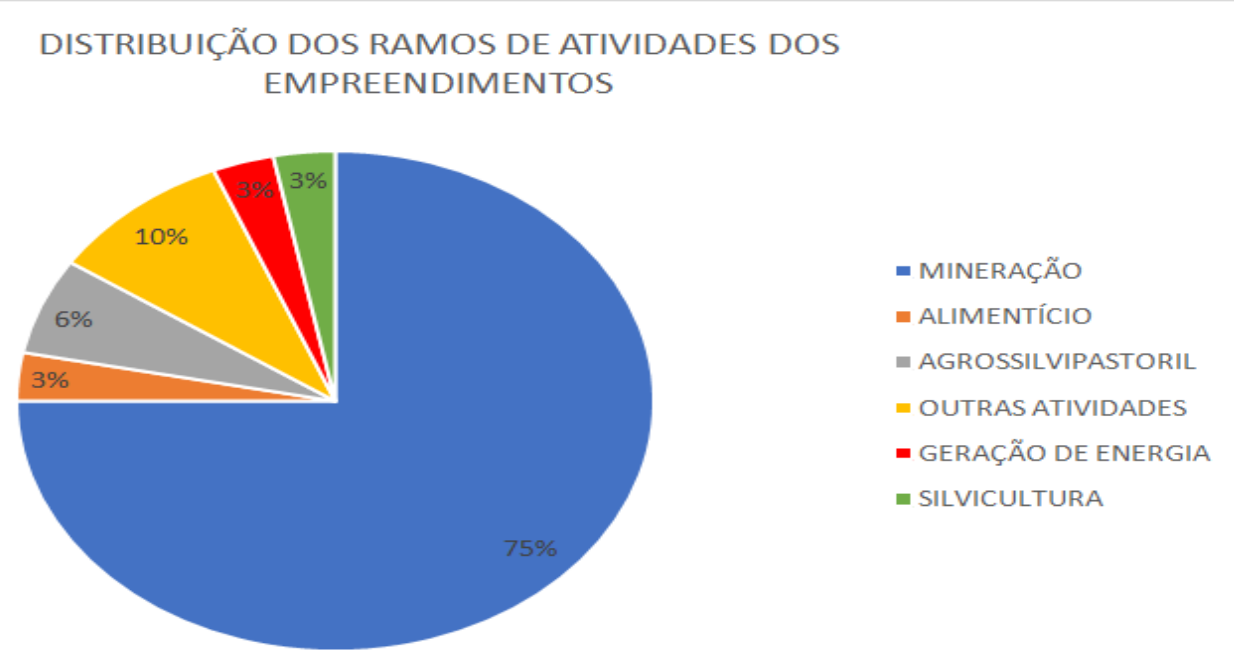

Figura 3. Análise da distribuição por segmentos dos empreendimentos licenciados EIA/RIMA no sul de Minas Gerais entre os anos de 2015 e 2019. 
RELAÇÃO DA QUANTIDADE DE EMPREENDIMENTOS QUE CITA NO

EIA/RIMA PROGRAMAS DE EDUCAÇÃO AMBIENTAL

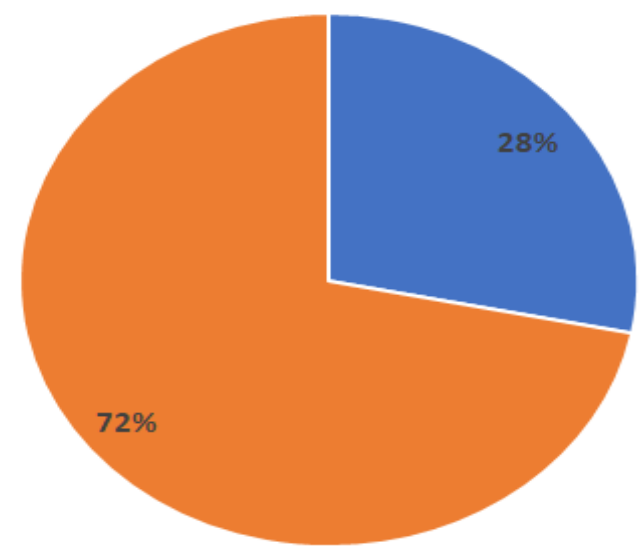

- NÃO CITA

- CITA

Figura 4. Porcentagem referente ao número de empreendimentos licenciados EIA/RIMA no sul de Minas Gerais entre os anos de 2015 e 2019, que apresentam Programas de Educação Ambiental como medida mitigadora.

A presente pesquisa limitou-se em considerar se os empreendimentos citam ou não a educação ambiental no EIA/RIMA, porém o maior problema encontrado foi que alguns citavam a educação ambiental em apenas uma linha, ou seja não apresentavam um programa estruturado. Além desse problema, nove empreendimentos em nenhum momento citaram as palavras "educação ambiental".

Segundo o Conselho Estadual de Política Ambiental (COPAM), por meio da Deliberação Normativa COPAM no 214/2017, estabelece os procedimentos e a execução dos Programas de Educação Ambiental no Estado de Minas Gerais, sendo esse programa necessário na apresentação do Estudo e Relatório de Impacto Ambiental (Minas Gerais, 2017). A partir dessa informação, tornou-se possível indagar como foi possível um empreendimento licenciado em 2018 e mais dois empreendimentos licenciados no mesmo ano dessa normativa, obterem essa licença sendo que ambos não citavam o programa.

De acordo com Magalhães e Loureiro (2016), os processos de implementação de projetos de educação ambiental são necessários para evitar conflitos ambientais, porém tais problemas só podem ser mitigados a partir do momento todas as classes sociais estejam engajadas com o mesmo propósito.

Também é necessário expor que esta disciplina é recente, e além da possibilidade de seu conteúdo não ser devidamente absorvido no ensino formal, há grande quantidade de pessoas que obtiveram este conhecimento por terem frequentado o ensino formal antes dessas diretrizes. Assim, busca-se diminuir essa falta de conhecimento por meio de leis, diretrizes e normas, as quais incluem a obrigatoriedade de Programas de Educação Ambiental no processo de licenciamento.

Além de $28 \%$ dos empreendimentos com EIA/RIMA não citar ou abordar a educação ambiental, que é um requisito legal, muitos dos outros $72 \%$ não tinham também um programa estruturado para tratar efetiva e adequadamente o tema, que na sua essência busca promover a integração entre empresa, sociedade e meio ambiente, além de ser ferramenta importante para garantir a conservação ambiental. Isso nos leva ao entendimento de que na maioria dos casos a educação ambiental é tratada em programas 
apenas como cumprimento de um requisito legal e não como ferramenta de conscientização e informação.

É preciso lembrar que o estado de Minas Gerais já é marcado por desastres ambientais, como o rompimento da barragem da Indústria Cataguases de Papel, no Município de Cataguases em 2003, o rompimento da barragem de rejeitos da mineradora Samarco, em Mariana (2015) e em 2019 o rompimento da barragem de rejeitos da Vale, mina córrego do Feijão, em Brumadinho, com prejuízos sociais, financeiros e ambientais incalculáveis, com repercussões até os dias atuais. Em todos os acidentes foram marcantes a falta de comunicação entre os envolvidos, além da clara falta de transparência e informações a respeito dos empreendimentos, o que reforça a necessidade de programas eficientes de educação ambiental em todas as fases dos empreendimentos de explotação de recursos naturais, desde o planejamento até o funcionamento.

\section{Conclusão}

O estudo mostrou que a educação ambiental é negligenciada nos processos de licenciamento e funcionamento de empreendimentos licenciados com EIA/RIMA. Considerando que esta disciplina é um instrumento de conscientização social e também da importância do próprio empreendimento em si, os programas precisam de maior robustez e integração entre as partes envolvidas para efetivamente ser um instrumento ativo no cotidiano das empresas e de seus funcionários.

Como ponto de melhoria para os respectivos empreendimentos, a necessidade de tornar a educação ambiental um pilar estratégico para o negócio é fundamental, tanto em termos legais, quanto em conjuntura ambiental e social, aproximando a sociedade dos empreendimentos e reduzindo custos de conflitos sociais, cada vez mais comuns na instalação e funcionamento de empreendimentos de explotação de recursos naturais.

Ainda, considerando que a educação ambiental é programa obrigatório nos processos de licenciamento ambiental, especialmente por EIA/RIMA, estes processos podem estar infringindo normas administrativas, além de não promover conscientização e publicidade aos processos e aos empreendimentos.

\section{Agradecimentos}

Ao Programa de Pós-Graduação da Universidade Federal de Alfenas e ao apoio da Coordenação de Aperfeiçoamento de Pessoal de Nível Superior - Brasil (CAPES) - Código de Financiamento 001.

\section{Conflito de interesses}

Os autores declaram não haver conflito de interesses.

\section{Referências}

Brasil. Procedimentos de licenciamento ambiental do Brasil. 2. ed. Brasília: MMA, 2016.

Brasil. Programa Nacional de Capacitação de Gestores Ambientais: licenciamento ambiental. Brasília: MMA, 2009.

Brasil. Lei no 6.938, de 31 de agosto de 1981. Dispõe sobre a Política Nacional do Meio Ambiente, seus fins e mecanismos de formulação e aplicação, e dá outras providências. Disponível em: <http://www.planalto.gov.br/ccivil_03/LEIS/L6938.htm>. Acesso em: 23 maio 2020. 
Brasil. Resolução CONAMA no 001, de 23 de janeiro de 1986. Dispõe sobre critérios básicos e diretrizes gerais para a avaliação de impacto ambiental. Disponível em: <http://www2.mma.gov.br/port/conama/legislacao/CONAMA_RES_CONS_1986_001.pdf> . Acesso em: 23 maio 2020.

Brasil. Constituição da República Federativa do Brasil de 1988. Disponível em: <http://www.planalto.gov.br/ccivil_03/constituicao/constituicaocompilado.htm>. Acesso em: 23 maio 2020.

Brasil. Resolução CONAMA no 237, de 19 de dezembro de 1997. Disponível em: <http://www2.mma.gov.br/port/conama/res/res97/res23797.html>. Acesso em: 23 maio 2020.

Gil, A. C. Métodos e técnicas de pesquisa social. 5. ed. São Paulo: Atlas, 1999.

Magalhães, N.; Loureiro, C.F. B. A institucionalização da educação ambiental no licenciamento: uma política para a participação social na gestão ambiental pública. Revista Pesquisa em Educação Ambiental, v. 11, n. 1, p. 125-137, 2016.

Milaré, E. Direito do ambiente. 10. ed. São Paulo: Revista dos Tribunais, 2018.

Minas Gerais. Decreto no 45.629, de 06 de julho de 2011. Altera o Decreto no 45.175, de 17 de setembro de 2009, que estabelece metodologia de gradação de impactos ambientais e procedimentos para fixação e aplicação da compensação ambiental. Disponível em: <https://www.legisweb.com.br/legislacao/?id=142672>. Acesso em: 23 maio 2020.

Minas Gerais. Secretaria de Estado de Meio Ambiente e Desenvolvimento Sustentável SEMAD. Estudos passíveis de EIA/Rima. 2020. Disponível em: <http://www.meioambiente.mg.gov.br/licenciamento/370>. Acesso em: 15 mar. 2020.

Minas Gerais. Deliberação Normativa COPAM no 214, de 26 de abril de 2017. Estabelece as diretrizes para a elaboração e a execução dos Programas de Educação Ambiental no âmbito dos processos de licenciamento ambiental no Estado de Minas Gerais. Disponível em: <http://www.siam.mg.gov.br/sla/download.pdf?idNorma=44198>. Acesso em: 23 maio 2020.

Pereira, V. D.; Gutierres, H. E. P. Análise da distribuição territorial dos empreendimentos com EIAS/RIMAS no Estado da Paraíba nos anos de 2003 a 2014. Revista de Geográfica, v. 35, n. 3, p. 177-196, 2018.

SEBRAE - Serviço Brasileiro de Apoio às Micro e Pequenas Empresa. Manual de licenciamento ambiental: guia de procedimento passo a passo. Rio de Janeiro: GMA, 2004.

SIAM - Sistema Integrado de Informação Ambiental. Lei no 21.972, de 21 de janeiro de 2016. Dispõe sobre o Sistema Estadual de Meio Ambiente e Recursos Hídricos - Sisema - e dá outras providências. Disponível em: <http://www.siam.mg.gov.br/sla/download.pdf? idNorma=40095>. Acesso em: 15 mar. 2020.

Informação da Licença: Este é um artigo Open Access distribuído sob os termos da Licença Creative Commons Attribution, que permite uso irrestrito, distribuição e reprodução em qualquer meio, desde que a obra original seja devidamente citada. 